\title{
Design and Fabrication of the KOMAC RFQ
}

\author{
J. M. Han, Y. S. Cho, B.J. Yoon and B. H. Choi, KAERI, Korea \\ Y. S. Bae and I. S. Ko, POSTECH, Korea \\ B. S. Han, SHI, Korea \\ Y. Oguri, TIT, Japan
}

\section{Abstract}

A RFQ linac $(3 \mathrm{MeV}, 350 \mathrm{MHz}, 20 \mathrm{~mA}, \mathrm{CW}$ and $324 \mathrm{~cm}$ in length) is being built for the Korea Multipurpose Accelerator Complex (KOMAC). The physical and engineering design of the $\mathrm{H}^{+} / \mathrm{H}^{-}$RFQ linac are described. The fabrication process for the cold model and structure support is described. The current status of the RFQ is reported.

\section{INTRODUCTION}

The Radio-Frequency Quadrupole (RFQ) linac, which will produce a $20 \mathrm{~mA}$ beam of $\mathrm{H}^{+} / \mathrm{H}^{-}$with the energy of $3 \mathrm{MeV}$, was proposed for the Korea Multipurpose Accelerator Complex (KOMAC) [1-4]. This paper presents the physics and engineering design plus the fabrication status of the KOMAC RFQ. The RFQ concept is shown in Fig. 1 with the parameter values given in Table 1.

The main focuses of this physics and engineering design in the RFQ are as follows:

- To understand the transmission of the mixing $\mathrm{H}^{+} / \mathrm{H}^{-}$ beam into the RFQ.

- To obtain the tuning frequency by undercutting the end regions of the vane.

- To determine the locations and shapes of the coolant passages.

- To determine the shape of the brazing surface.

The physics and engineering design study is presented in section 2. Section 3 describes the fabrication status of the KOMAC RFQ.
Table 1. RFQ Linac Parameters.

\begin{tabular}{|l|l|}
\hline \multicolumn{1}{|c|}{ PARAMETER } & \multicolumn{1}{c|}{ VALUE } \\
\hline Operating frequency & $350 \mathrm{MHz}$ \\
\hline Particles & $\mathrm{H}^{+} / \mathrm{H}$ \\
\hline Input / Output Current & $21 / 20 \mathrm{~mA}$ \\
\hline Input / Output Energy & $0.05 / 3.0 \mathrm{MeV}$ \\
\hline $\begin{array}{l}\text { Input / Output Emittance, } \\
\text { Transverse/norm. }\end{array}$ & $\begin{array}{l}0.02 / 0.023 \pi-\mathrm{cm}-\mathrm{mrad} \\
\mathrm{rms}\end{array}$ \\
\hline $\begin{array}{l}\text { Output Emittance, } \\
\text { Longitudinal }\end{array}$ & $0.246 \mathrm{MeV}-\mathrm{deg}$ \\
\hline Transmission & $95 \%$ \\
\hline RFQ Structure Type & $4-\mathrm{vanes}$ \\
\hline Duty Factor & $100 \%$ \\
\hline Peak Surface Field & $1.8 \mathrm{Kilpatrick}$ \\
\hline Structure Power & $350.0 \mathrm{~kW}$ \\
\hline Beam Power & $67.9 \mathrm{~kW}$ \\
\hline Total Power & $417.9 \mathrm{~kW}$ \\
\hline Length & $324.0 \mathrm{~cm}$ \\
\hline
\end{tabular}

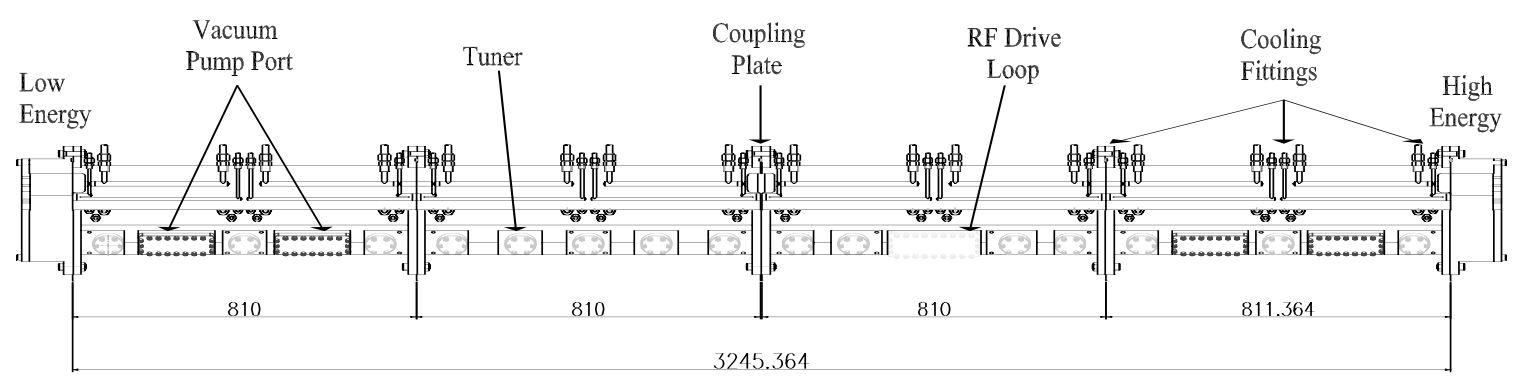

Figure 1. 3MeV, cw KOMAC RFQ Drawing. 


\section{PHYSICS AND ENGINEERING DESIGN}

The motion of the mixing $\mathrm{H}^{+} / \mathrm{H}^{-}$beam into the RFQ has beeb studied by using a time marching beam dynamics code QLASSI [5]. Fig. 2 shows the dependence of the beam transmission rate and the $\mathrm{H}^{-}$mixing ratio. The longitudinal beam loss increases with the concentration of negative ions by the bunching process which is distributed by attractive forces. Because of the space charge compensation in the low energy sections, the transverse beam loss decreases with the mixing ratio of $\mathrm{H}$. In the KOMAC RFQ, the mixing ratio of $\mathrm{H}^{-}$is less than $10 \%$.

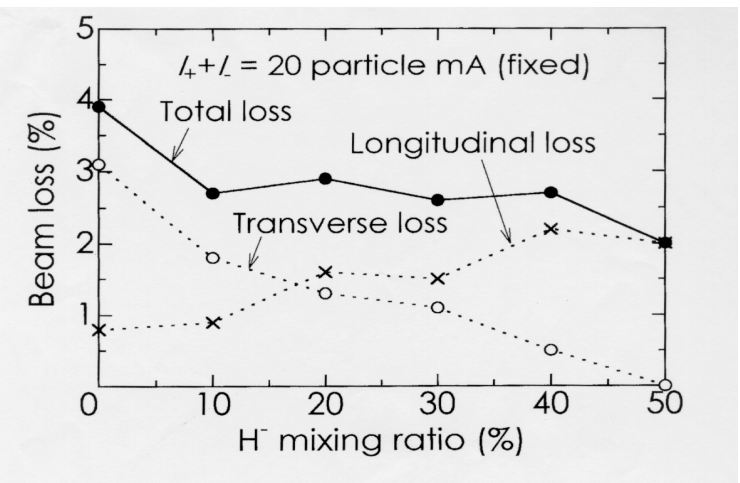

Figure 2. Dependence of Beam Transmission Rate and $\mathrm{H}$ Mixing Ratio.

In general, most of the RFQ structure can be understood in a two-dimension model. However, the end regions and the joints need full three-dimensional modelling. These regions have been investigated with the threedimensional electromagnetic code, MAFIA [6]. Fig. 3 shows a three-dimensional simulation model of the end region of the RFQ. The end-gap distance and undercutting depth were varied until the quadrupole mode frequency of the model was tuned to $350.3 \mathrm{MHz}$. In this case, the end-gap distance and undercutting depth are $7.5 \mathrm{~cm}$ and $2.7 \mathrm{~cm}$, respectively. Fig. 4 shows the

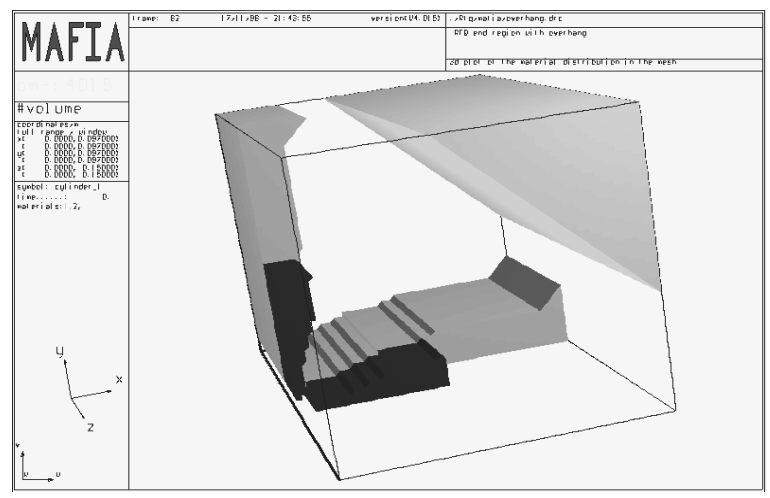

Figure 3. 3D Simulation Model of the End Region.

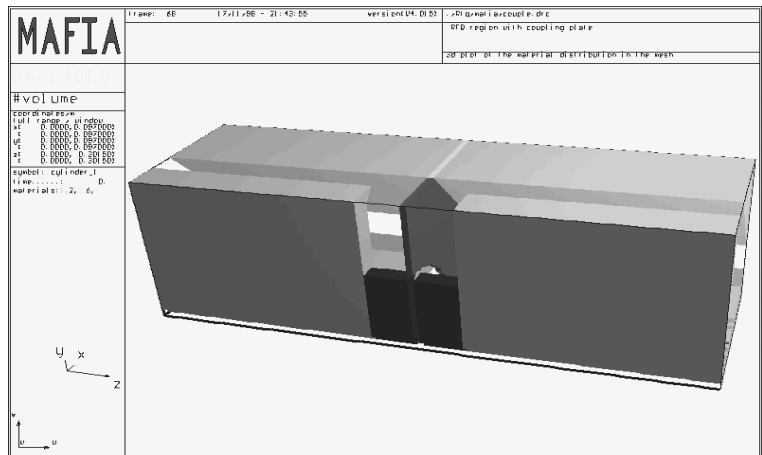

Figure 4. 3D Simulation Model of a Two-Section Coupled RFQ

MAFIA model of a two-section coupled RFQ. The simulation result has shown that a $0.205 \mathrm{~cm}$ coupling gap-distance, a $2.5 \mathrm{~cm}$ undercutting depth and $5.2 \mathrm{~cm}$ coupling plates inner radius results in a near optimum separation between the quadrupole modes. Results simulated by the MAFIA models will be tested on a cold model which has been fabricated with Al6063.

In the design of the coolant passages, we considered the thermal behaviour of the vane during $\mathrm{CW}$ operation and manufacturing costs. The thermal and structure analysis is studied with SUPERFISH [7] and ANSYS codes. The average structure power by rf thermal loads is $0.35 \mathrm{MW}$ and the peak surface heat flux on the cavity wall is 0.13 $\mathrm{MW} / \mathrm{m}^{2}$ at the high energy end. In order to remove this heat, we consider 48 longitudinal coolant passages in each of the sections, as shown in Figs. 1 and 5. Fig. 5 shows a thermal distribution of the cavity at the high energy end. The material is oxygen-free highconductivity copper (OFHC). The thermal loads were given by SUPERFISH analysis. The heat transfer coefficients are between $11 \mathrm{~kW} / \mathrm{m}^{2}-\mathrm{C}$ to $15 \mathrm{~kW} / \mathrm{m}^{2}-\mathrm{C}$.

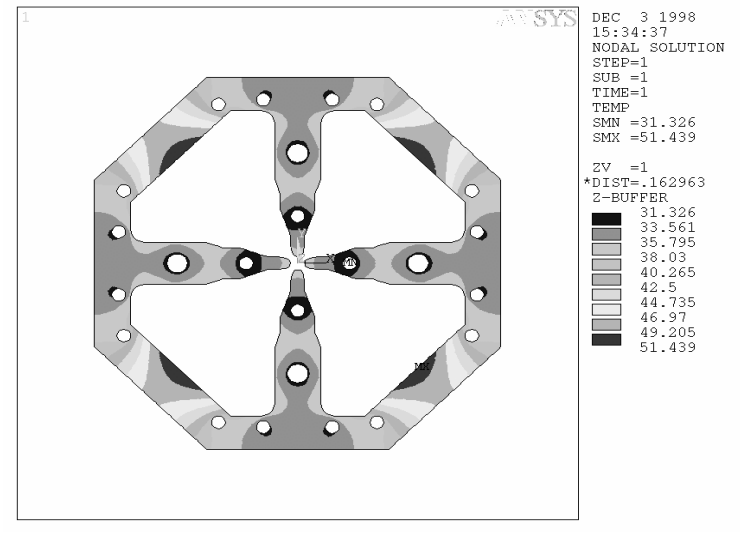

Figure 5. Temperature Distribution of the Cavity at the High Energy End of the KOMAC RFQ. 
Because of the flow erosion of the coolant passages, we consider the maximum allowable bulk velocity of the coolant as $4.5 \mathrm{~m} / \mathrm{sec}$. From the thermal-structural analysis of ANSYS, the peak temperature on the cavity wall is $51.4{ }^{\circ} \mathrm{C}$, the maximum displacement is $42 \mu \mathrm{m}$ and the intensity stress is $13 \mathrm{MPa}$. We use the cooling tower on the cavity walls and the refrigeration system on the vane area. For rf tuning, the coolant passages on the vane area are operated with $10{ }^{\circ} \mathrm{C}$ coolant. However the temperature of the coolant of the passages on the cavity wall is varied to maintain the cavity on resonance frequency. The coolant passages in the cavity wall and vane area are the deep-hole drilled. The entrances of deep holes at the vane end are brazed.

\section{FABRICATION STATUS}

The RFQ cold model was fabricated with Al6063, as shown in Fig. 6, and the field test with the beadpull perturbation technique will begin next week. A bead is metal and is drawn through the four quadrants of the RFQ near the outer wall.

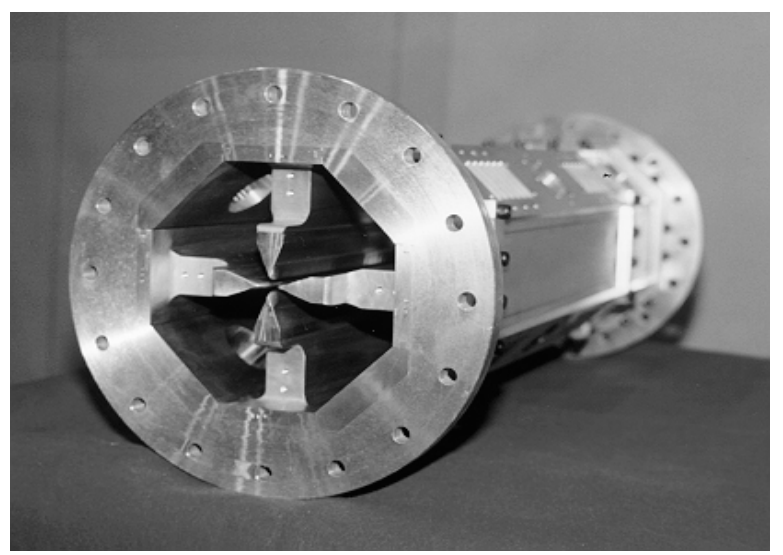

Figure 6. A Section of the KOMAC RFQ Cold Model.

The four quadrants of the RFQ are fabricated separately and brazed. Because of the leak of the brazing surface and the strain of the RFQ structure by furnace heat, it is important to determine the exact shape of brazing area[8]. Fig. 7 shows an $81 \mathrm{~cm}$ long brazing test unit. The test unit was brazed in a vertical orientation with LUCAS Bag-8, a AgCu alloy with a liquids temperature of $780{ }^{\circ} \mathrm{C}$.

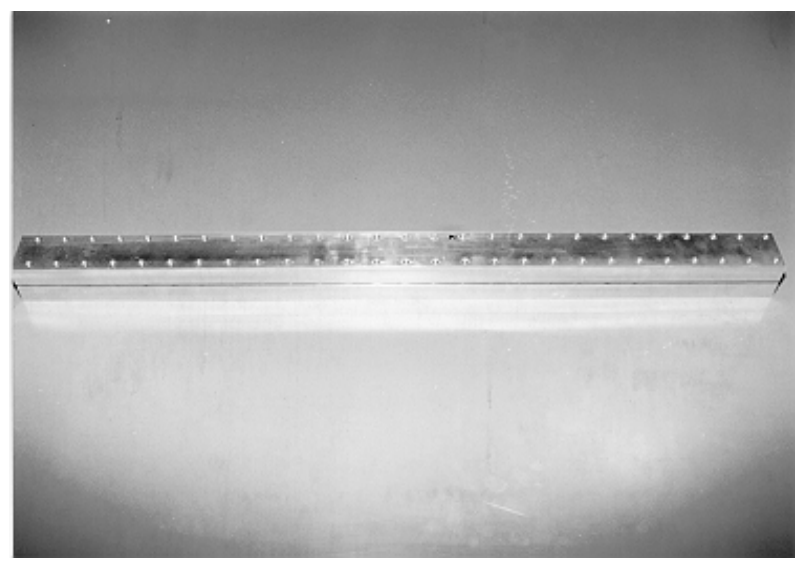

Figure 7. Brazing Test Unit.

At the present time, new brazing test unit is being brazed and one of the four sections is being fabricated.

\section{ACKNOWLEDGMENT}

We are grateful to Dr. Yanglai Cho at ANL, Y. Y. Lee at BNL, Dr. Kazuo Hasegawa at JAERI and Dr. Lloyd M. Young at LANL. This work has been supported by the Korea Ministry of Science and Technology (MOST).

\section{REFERENCES}

[1] C. K. Park et al., "The Komac Project: Accelerator and Transmutation Project in Korea", Proceeding of APAC98, Tsukuba, (1998).

[2] Y. S. Cho et al., "Conceptual Design Study of KOMAC DTL", Proceeding of APAC98, Tsukuba, March 23-27 (1998)

[3] J. M. Han et al, "Design of the KOMAC $\mathrm{H}^{+} / \mathrm{H}$ RFQ Linac", Proceeding of LINAC98, Chicago, (1998)

[4] B. H. Choi, "KOMAC", OECD NEA Workshop, (1998).

[5] Y. Oguri et al., "Beam Tracking in an RFQ Linac with Small Vane-Tip Curvature", Nuclear Sci. Tech., 30, 477 (1993).

[6] R. Klatt et al., "MAFIA-A Three-Dim. Electromagnetic CAD System for Magnets, RF Structures, and Transient Wake-field Calculations", SLAC-303, 276 (1986).

[7] J. H. Billen and L. M. Young, "POISSON SUPERFISH", LA-UR96-1834 (Revised December, 1997).

[8] D. Schrage et al., "A New RFQ Linac Fabrication Technique”, LA-UR-94-2483, (1994). 